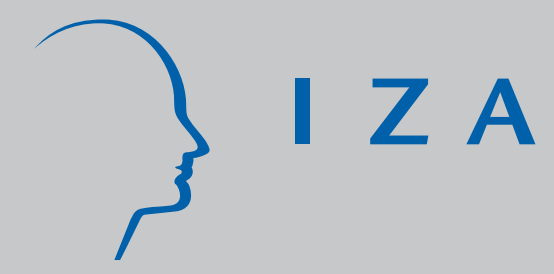

IZA DP No. 3817

Does Retirement Kill You?

Evidence from Early Retirement Windows

Norma B. Coe

Maarten Lindeboom

November 2008 


\title{
Does Retirement Kill You? Evidence from Early Retirement Windows
}

\author{
Norma B. Coe \\ Tilburg University, Netspar \\ and CentER
}

Maarten Lindeboom

VU University of Amsterdam, Tinbergen Institute, HEB, Netspar and IZA

\section{Discussion Paper No. 3817 \\ November 2008}

\author{
IZA \\ P.O. Box 7240 \\ 53072 Bonn \\ Germany \\ Phone: +49-228-3894-0 \\ Fax: +49-228-3894-180 \\ E-mail: iza@iza.org
}

\begin{abstract}
Any opinions expressed here are those of the author(s) and not those of IZA. Research published in this series may include views on policy, but the institute itself takes no institutional policy positions.

The Institute for the Study of Labor (IZA) in Bonn is a local and virtual international research center and a place of communication between science, politics and business. IZA is an independent nonprofit organization supported by Deutsche Post World Net. The center is associated with the University of Bonn and offers a stimulating research environment through its international network, workshops and conferences, data service, project support, research visits and doctoral program. IZA engages in (i) original and internationally competitive research in all fields of labor economics, (ii) development of policy concepts, and (iii) dissemination of research results and concepts to the interested public.
\end{abstract}

IZA Discussion Papers often represent preliminary work and are circulated to encourage discussion. Citation of such a paper should account for its provisional character. A revised version may be available directly from the author. 
IZA Discussion Paper No. 3817

November 2008

\section{ABSTRACT \\ Does Retirement Kill You? Evidence from Early Retirement Windows*}

The magnitude of the effect that health has on the retirement decision has long been studied. We examine the reverse relationship, whether or not retirement has a direct impact on laterlife health. In order to identify the causal relationship, we use unexpected early retirement window offers to instrument for retirement behavior. They are legally required to be unrelated to the baseline health of the individual, and are significant predictors of retirement. We find that there is no negative effect of early retirement on men's health, and if anything, a temporary increase in self-reported health and improvements in health of highly educated workers. While this is consistent with previous literature using Social Security ages as instruments, we also find some evidence that anticipation of retirement might also be important, and might bias the previous estimates towards zero.

JEL Classification: I12, J08, J14

Keywords: health, retirement, instrument, causal effect

Corresponding author:

Norma B. Coe

Tilburg University

K436

P.O. Box 90153

5000 LE Tilburg

The Netherlands

E-mail: N.Coe@uvt.nl

\footnotetext{
* We would like to thank Rob Alessie, James Banks, Gerard van den Berg, Katie Carman, Arie Kapteyn, Alan Gustman, Gema Zemarro, and Aico van Vuuren for comments and suggestions. Furthermore we acknowledge the participants of the workshop on "Income, Health and Work across the Life Cycle", December 2006 in Amsterdam and participants of seminars at Netspar, Tilburg University, University of Mannheim, Aarhus University, the Boston College Center for Retirement Research, RAND, and the Utrecht School for Economics for helpful comments. Coe thankfully acknowledges financial support from the European Union under the Marie Curie Incoming International Fellowship. All remaining errors are our own.
} 


\section{Introduction}

"They say the number one killer of old people is retirement." - Budd, Kill Bill Vol 2

What are the health effects of the act of retiring? While this is an important question with pertinent policy consequences, little is currently known about the answer. As talk of raising retirement ages in pensions and social security schemes continues around the world, it is important to know both the costs and benefits for the individual as well as the government or pension fund's budgets and health care expenditures.

The notion that retirement harms health is an old and persistent hypothesis. (See Minkler 1981 for a review.) Many argue that retirement itself is a stressful event (Carp 1967, Eisdorfer and Wilkie 1977, MacBride 1976, Sheppard 1976). This stressful event could lead to increased illness susceptibility. Even for those for whom retirement is not a stressful event, it still can lead to a break with support networks and friends, and may be accompanied by emotional or mental impacts of "loneliness," "obsolescence," or "feeling old" (Bradford 1979, MacBride 1976). If retirement has a negative net affect on health, then increasing the retirement age may lead to better overall health for individuals and an improved budgetary outlook for the government.

Others believe that retirement is a health-preserving life change. Anecdotal evidence suggests that many "kitchen table" discussions about the timing of retirement include the idea that work is stressful and taxing to the individual, thus retirement would remove this stress and preserve the health of the retiree (Ekardt et al, 1983).

Despite the long-standing debate, there is little conclusive evidence thus far. The question is much more difficult to answer than would appear at first glance. The inherent problem is that retirement is often a choice and health may have a direct impact on the decision to retire. Furthermore there are unobservable factors that may confound the health and work relationship. Many of the early studies do not address this, and thus can only infer association, not causation. Compounding the problem is that some of these early studies find a positive correlation with health (Thomson et al 1958), no correlation with health (Carp 1977, Atchey 1976, Kasl 1980, Rowland 1977, Haynes et al 1978, Niemi 1980, Adams and Lefebvre 1981), or a negative correlation with health (Casscells et al 1980, Gonzales 1980).

Properly addressing the endogeneity of retirement behavior and health is a difficult task. Identification of the causal relations between health and labor market outcomes requires independent variation in either health or work status to assess the effect of one on the other. More 
recent papers acknowledge this, but have problems directly dealing with it. Tsai et al (2005) measure the post- 65 retirement mortality rates for individuals, regardless of the age of retirement. While they find that those retired at age 55 do have higher post-65 mortality rates, the hypothesis that earlier health problems lead to the early retirement behavior cannot be rejected. Further, since they only examine mortality rates, more subtle changes in health outcomes may be overlooked. Kerkhofs and Lindeboom (1997) assess the effects of work history on the health status of older workers using fixed effects regressions. This accounts for time invariant factors that may confound the results, but it does not account for time varying factors such as a sudden change in the individual environment. Their results suggest that health deteriorates with increased work efforts and that increasing retirement ages may negatively influence later life health outcomes. Lindeboom et al (2002) look at the effect of life events on the mental health of older individuals. These life events include retirement and they try to control for all transitory changes as well as individual fixed-effects. They find no statistical effect of loss of work with mental health measured 2-years later. This does not address any physical health affects of retirement, either positive or negative, and actually controls for all physical health deterioration that is observed in the data. Thus, this may fail to measure the true cumulative impact of retirement on physical and mental health.

In order to assess the causal impact of retirement on health, one needs to find an instrument that is related to retirement behavior, but uncorrelated with health. Charles (2002) and Neuman (2007) use age specific retirement incentives provided by the US Social Security regulations. The US Social Security system provides strong retirement incentives at ages 62, 65, 70 and 72 and these age cutoffs can be used to identify the effect of retirement on age, assuming there are no discontinuous changes in health at these ages except those induced by retirement. Charles (2002) focuses on mental well-being and finds that the direct effect of retirement on mental well-being is positive, once the fact that retirement and mental well-being are jointly determined is accounted for. Neuman (2007) uses both subjective and more objective measures of health. He finds that retirement preserves subjective health for both men and women. For the objective measures he does not find an effect of retirement. Bound and Waidmann (2008) use institutional features of the UK pension system that are exogenous to the individual and find no evidence of negative health effects of retirement. For men they find some evidence for a positive effect of retirement on health. Coe and Zamarro (2008) use institutional features of the pension systems throughout continental Europe, and find a health preserving effect of retirement for men. 
In this paper we consider a broad set of health indicators, including mortality, for both blue- and white-collar workers. For the identification of the causal effect we acknowledge that age specific retirement incentives of the US Social Security system may aid in the identification of the health effects of retirement, but in addition exploit sudden changes in retirement opportunities in order to assess the health effect of retirement. Data from the Health and Retirement Survey (HRS) includes information on the offering, and acceptance, of early retirement windows. Early retirement windows are special incentives to retire at a specific time offered by employers to employees. The offering of early retirement windows is exogenous to an individual's health. While it is in the company's best interest to limit the early retirement windows to the least productive members of the company, this may or may not be orthogonal to health status of the workers. In addition, while management can select groups of workers to be eligible for early retirement windows, their power to limit eligibility is limited by the courts (987 F. Supp. 1115, S.D. Ind. 1997, ruled that the eligibility decisions cannot be seen as "arbitrary and capricious."). We conclude from analyses of our data that the offering of a retirement window can indeed be considered as exogenous in our sample. Retirement windows generally allow workers to retire at substantially younger ages than age 62 , the earliest opportunity for benefits provided by Social Security. Thus we add substantial exogenous variation in the retirement date that can be used to identify the causal effect of retirement on health and mortality.

\section{$2 \quad$ A simple model for health and work}

Let us start with a simple framework for modeling the potential relationship between health and work. Let us assume that retirement is an absorbing state ${ }^{1}$, and an individual worker chooses the retirement date that maximizes life time utility, $V_{t}=U\left(y_{t}, y_{t+1}, \ldots, y_{T}, H_{t}, H_{t+1}, \ldots, H_{T}\right)$, where $y_{t}$ is the income in period $t, H_{t}$ health in period $t$ and $T$ is the maximum age attainable. We assume that

$$
V_{t}=\sum_{\tau=t}^{T} \beta^{\tau-t} u_{t}\left(y_{t}, H_{t}\right)
$$

\footnotetext{
${ }^{1}$ This might not be reasonable for the US with the increased frequency of "bridge-jobs", but this seems less important in this case due to using early retirement windows as an instrument, where few return to work (see Brown 2002.) 
with $u_{y}>0, u_{y y}<0, u_{H}>0$ and $u_{H H}<0$. When at work an individual receives income $y_{t}=w_{t}$, when retired $y_{t}=B_{t}$, with $w_{t}>B_{t}$. Work yields a per-period utility of $u_{t}=w_{t} H_{t}-\alpha$, with $\alpha$ being the disutility of work, and non-work (retirement) $u_{t}=B_{t} H_{t}$.

The relation between $B_{t}$ and $w_{t}$ is determined by the rules of the retirement system. Generally it is the case that continued work is associated with higher benefit levels. Another source of dynamics in this model is that the work choices may affect health. Work, or aspects of work, may cause health to decline at a faster rate $^{2}$. Also, individual health may change after retirement, for instance due to changes in the individual context, the social network and psychological changes after retirement. A priori it is not clear whether retirement would cause health to decrease at a faster or slower rate.

According to the structure of the model the individual chooses the optimal date of retirement, taking into account the health effects of retirement and the effect of continued work on retirement income. Suppose that there are two periods and that an individual has to decide to retire at the normal mandatory retirement age (period 1), or at an earlier age (period 0). Retirement at period 0 gives a benefit $b$, retirement at a later age gives benefit $b^{+}$. So early retirement provides income $y_{0}=B_{0}=b^{-}$during period 0 and $y_{1}=B_{1}=b$, during period 1 . Health remains at its initial level $H_{0}$ during period 0 , but the decision to retire or not affects health after retirement (period 1). More specifically, we assume that health becomes $H_{S}$ if the individual stops working (retires) at age 0 and becomes $H_{W}$ if (s)he continues working (delays retirement until period 1). $H_{W}$ and $H_{S}$ can be interpreted as the flow of health up to death. Thus the value of retiring at the start of period 0 equals:

$$
V_{0}^{S}=b^{-} H_{0}+\beta b^{-} H_{S}
$$

with $\beta$ a discount factor. The value of continued work (retiring in period 1) equals:

$$
V_{0}^{W}=w H_{0}-\alpha+\beta b^{+} H_{W}
$$

So an individual retires at an early date if and only if

$$
\begin{aligned}
V_{0}^{S}>V_{0}^{W} & \Leftrightarrow b^{-} H_{0}+\beta b^{-} H_{S}>w H_{0}-\alpha+\beta b^{+} H_{W} \\
& \Leftrightarrow H_{0}\left(b^{-}-w\right)+\beta H_{S}\left(b^{-}-b^{+}\right)+\beta b^{+}\left(H_{S}-H_{W}\right)+\alpha>0
\end{aligned}
$$

\footnotetext{
${ }^{2}$ The rate of deterioration may also depend on the kind of work. We ignore this in the simple model, but will estimate separate models for blue- and white-collar workers.
} 
Equations (3) states that for the early retirement decision the current and long run monetary costs of immediate retirement (the first two terms) should be balanced with the disutility and the health cost of later retirement. A priori we do not want to impose whether $H_{S}$ is smaller or larger than $H_{W}$. Retirement is delayed when the health effects of later retirement are relatively small or even positive ( $H_{W}$ is relatively high), the monetary gains of continued work are high $\left(b^{+}\right.$high relative to $\left.b^{-}\right)$and the disutility of work $(\alpha)$ is low. So changes in the parameters of the retirement system will affect the work continuation decision and will consequently also affect the average health condition of the retirees in the last stage of life. Suppose for instance that individuals vary with respect to their disutility of work and that $\alpha$ is randomly distributed. Then the average health of retirees in period 1 equals:

$$
\overline{H_{1}}=p H_{S}+(1-p) H_{W}
$$

With $p=\operatorname{Pr}\left(V_{0}^{S}>V_{0}^{W}\right)=\operatorname{Pr}\left(\alpha>H_{0}\left(w-b^{-}\right)+\beta H_{S}\left(b^{+}-b^{-}\right)+\beta b^{+}\left(H_{W}-H_{S}\right)\right)$. Low initial replacement rates $\left(b^{-} / w\right)$ and high benefit accrual rates $\left(b^{+}-b^{-}\right.$is large) stimulate later retirement (small $p$ ) so that a larger fraction of the population will continue working. As a consequence average post retirement (period 1) population health will decrease (if $H_{W}<H_{S}$ ) or increase (if $H_{W}$ $>H_{S}$ ). This important side-effect of retirement policy on health, and related health care costs, needs to be taken into account when considering changes in retirement policy and its effects on the overall government budget.

Some remarks remain before we return to the empirical model. First, extending the 2period model to a multi-period model will not alter the basic results of the model. For instance, suppose that retirement at age $t$ yields a benefit $B_{t}$ and continued work a wage $w_{t}$. The decision to retire can be written as a sequence of per period comparison of the value of continued work $\left(V_{t}{ }^{W}\right)$ with the value of immediate retirement $\left(V_{t}{ }^{S}\right)$, with:

$$
\begin{aligned}
& V_{t}^{W}=w_{t} H_{t}-\alpha+\beta E \max \left\{V_{t+1}^{W}, V_{t+1}^{S}\right\} \\
& V_{t}^{S}=B_{t} H_{t}+\beta E V_{t+1}^{S}
\end{aligned}
$$

An individual retires if $V_{t}{ }^{W}<V_{t}{ }^{S}$. Future health is included in the future value functions and in this way the individual worker takes the health effects of (non) retirement into account. One could make the development in health and how it relates to labor market choices more explicitly, for instance by taking the health production function suggested by Grossman (1972):

$$
H_{t+1}-H_{t}=I(t)-\delta H_{t}
$$


The health production function (7) relates the change in the health stock to the investment $I(t)$ and the depreciation of health $(\delta)$. The health investment can be a function of (medical), consumption and time investments in health, like the decision to continue or stop working. An empirical counterpart of (7) would boil down to a dynamic model where current health outcomes are related to past health, labor supply choices and other individual characteristics to capture other non-time health investments. We return to this in the next section.

Second, one could also make $T$ (the date of death) endogenous, for instance by assuming that death occurs if the health stock falls below a critical level, say $H^{*}$. If one believes that work will keep people active and that adverse health effects of work are small or absent, then it will take a longer time before health falls below the critical level. If, on the other hand one assumes that a worker's health deteriorates faster while at work, for instance because of work stress, bad working conditions etc, then death will arrive at an earlier date. In the simple model these effects are implicit in the composite post-retirement health constructs $H_{S}$ and $H_{W}$ and therefore these additions will not alter the basic mechanism.

\section{Analytical framework}

The ultimate goal is to assess the health effects of later (or earlier) retirement. We use the Health and Retirement Survey (HRS), described in detail in the next section. Implementation of the model requires us to be more specific about the relation between later life health and the retirement decision. We modify the health production function above (7) to fit our empirical framework. The health investment function $I(t)$ could be allowed to depend on labor market choices, such as the decision to retire, and other socio-demographic characteristics (to represent other health investments decisions). In line with this, one could relate an indicator for health at age $t+1$ to health at $t$, whether or not an individual has retired in period $[t, t+1], R_{t}$, and individual characteristics $X$ :

$$
H_{i t+1}=\gamma_{0}+\gamma_{1} R_{i t}+\gamma_{2} X_{i t}+\gamma_{1}^{t}+(1-\delta) H_{i t}+\varepsilon_{i t}
$$

Of course one could specify more general equations than ( $\left.7^{\prime}\right)$, for instance by allowing the time since retirement to have an effect or by allowing for heterogeneous effects. To extend on the latter, health effects may, for instance, differ with respect to occupation. The health effects of retirement from a job that requires manual work under adverse working conditions in the 
construction sector may be different from the health effects of a job that does not involve physical work in the service sector. We use equation (7') as a base specification, but will also estimate models for longer run health effects and models that allow for different effects for blue- and white-collar workers and other subgroups.

In the empirical analyses we will focus on individuals at work in [t-2] and look at their health outcomes at a later point in time. The parameter of interest is $\gamma_{1}$. As discussed earlier, assessing the causal effect of the act of retirement is not trivial. A forward-looking agent plans retirement, taking later life health (developments) into account. This means that the retirement status and (later life) health are jointly determined and that we need exogenous variation in the retirement decision to assess its causal effect on health.

One way to proceed is to look at changes in Social Security or pension regulations. Examples are Charles (2002) and Neuman (2007), who use age specific retirement incentives provided by the US Social Security regulations and (Charles 2002) changes in these due to the 1983 amendments. This method has also been employed in an international context: Bound and Waidmann (2008) use age specific retirement incentives of the UK pension system and Coe and Zamarro (2008) for continental Europe. The idea is that US Social Security system provides strong incentives towards retirement at ages $62,65,70$ and 72 . For the UK this is age 65 for males and age 60 for females, and range between age 60 and 65 for men in continental Europe. These studies use these age cutoffs to identify the effect of retirement on age, assuming there are no discontinuous changes in health at these ages except those induced by retirement. We will rely on exogenous variation induced by early retirement windows and return to the merits of this approach compared to the approaches by Charles (2002), Neuman (2007), Bound and Waidmann (2008) and Coe and Zamarro (2008) in subsection 3.1.c.

\subsection{Early Retirement Windows as an Instrument}

We use data from the Health and Retirement Study (HRS) that provide information on the offering of early retirement windows to individual workers and use this as an instrument for retirement. Early retirement windows are special incentives to retire at a specific time offered by employers to employees. These windows are often of a relatively short duration and offer enhanced retirement benefits for early retirement (for example, offering extra years of service for a defined benefit pension plan.) These are often offered to workers in "career" jobs, and are often offered by the employer as an attempt to reduce staff size. 


\section{1a Which companies offer an Early Retirement Window?}

Companies often offer early retirement windows as a way to reduce staff size without massive layoffs or harboring ill-will. According to a 1992 Towers Perrin survey, more than 20 percent of the 534 U.S. companies surveyed offered one or more retirement windows in the previous four years. The windows were most common in large companies in the manufacturing, utilities and banking industries. Eligibility for retirement incentives was based primarily on age and service, rather than pay level. On average, about 10 percent of the workforce was eligible for the special retirement benefits. Some companies that have offered early retirement windows in the past include Eastman Kodak, Du Pont, Exxon, Polaroid, Xerox, R.J. Reynolds, IBM, Ford and AT\&T (Time 1983 and Towers Perrin 1992).

A Watson Wyatt survey (2001) reports that among companies offering early retirement windows, 92 percent report that these offerings allowed them to meet their staff reduction targets. These reduction targets could exist due to recessions, mergers and acquisitions, or a change in corporate management models.

\section{1b Which employees are offered an Early Retirement Window?}

The offering of early retirement windows is exogenous to an individual's health. While it is in the company's best interest to only offer early retirement windows to the least productive members of the company, this is illegal. Early retirement windows are often targeted at specific units or divisions (Towers Perrin 1992). Management can select groups of workers to be eligible for early retirement windows, but their power to limit individual eligibility is limited by the courts. 987 F. Supp. 1115 (S.D. Ind. 1997) ruled that the eligibility decisions cannot be seen as "arbitrary and capricious." Further, employees interested in early retirement windows but ineligible for the offers companies make have a history of suing the company ${ }^{3}$, reducing the ability of the company to limit eligibility for early retirement window offerings to the least productive members of the labor force.

Brown (2002), using the Health and Retirement Study, examines the observable characteristics of those who are offered early retirement windows versus those who are not. He finds that those offered early retirement windows are actually in better health, on average, than those not offered the early retirement. This is due to the purpose and the general targeting of the

\footnotetext{
${ }^{3}$ See Krawczyk v. Harnischfeger Corp., 41 F.3d 276, 278-79 (7th Cir. 1994); Pokratz v. Jones Dairy Farm, 771 F.2d 206, 209 (7th Cir. 1985); Albert C. McNab, et al v General Motors Corp.; Lockheed Corp. v. Spink, 517 U.S. 882 (1996); Johnson v. Georgia-Pacific Corp., 19 F.3d 1184 (7th Cir. 1994); McGath v. Auto-Body North Shore, Inc., 7 F.3d 665 (7th Cir. 1993); Henn v. National Geographic Society, 819 F.2d 824 (7th Cir. 1987)) 
early retirement windows to "career" workers, who are less likely to be in physically demanding jobs. ${ }^{4}$ Further, one-third of those who are offered early retirement windows subsequently accept them. Brown (2003) finds that individuals who accept an offer through an early retirement window are more likely to experience a sharp decline in labor force participation. These individuals tend not to go to work elsewhere after this "buy-out". This suggests that being offered an early retirement window is a good instrument for actual retirement behavior. In section 4.1 we will formally test whether the offering of a retirement window is a strong predictor for retirement.

\section{1c Comparing the offering of windows with age specific retirement incentives as instruments}

There are some advantages of using the offering of a retirement window over the age specific retirement incentives provided by the US Social Security regulations (Charles 2002, Neuman 2007). First, the age specific retirement incentives are fully predictable from the individual's point of view. A first consequence of this is that workers may offset possible health effects of retirement by adjusting their behavior prior to these ages. This suggests that the effects of retirement may be biased towards zero, or even upwards (towards better health outcomes) when one uses these instruments. ${ }^{5}$ Another consequence of the predictability of the retirement date might be that the impact of the retirement decision might not coincide with the actual retirement date. For instance, there may be mental health effects prior to the retirement date if one is anticipating retirement for a long period (similar to an "Ashenfelter dip"). This has consequences for the specification of the retirement effect in health production models like (7'). Second, related to the above, the timing of the offering of a window is something that a worker cannot fully predict and therefore it is less likely that anticipation effects will affect health outcomes prior to the offering of the retirement window. Furthermore, this additional source of random variation in the retirement age aids in the identification of the causal effect. Smith (2003) follows a similar reasoning using unanticipated changes in health ("health shocks") to identify the causal effect of health on wealth. Third, a substantial share of the workforce retires before the official retirement ages. For instance, the Bureau of Labor Statistics indicates that the median retirement age for men is 62 years. In our sample retirement windows are offered from age 50 to age 70. This better reflects the retirement age distribution of male US workers.

\footnotetext{
${ }^{4}$ This may bias the results. For instance, the estimate will be biased towards zero if retirement has a negative effect on health. In the empirical analyses we will examine whether this is relevant for our sample and whether we need to restrict our analyses to specific types of workers.

${ }^{5}$ Assuming that the raw correlation between retirement age and health is negative.
} 
We include a section on the sensitivity of our findings with respect to our choice of instrument. We will test how the results are affected when we include age specific retirement incentives as additional instruments in the analysis.

\section{Data}

The data are from the Health and Retirement Study, conducted by the Survey Center of the University of Michigan. This is a longitudinal survey of people born in 1931-1941 and their spouses (regardless of age) starting in 1992 with follow-up interviews every 2 years. Currently, 7 waves of data are available (1992-2004). When weighted to account for initial over-sampling of some population groups and for subsequent attrition, the HRS provides a representative sample of those in this birth cohort.

The HRS collects substantial information about mental and physical health, using both objective and subjective measures. This allows one to test a variety of potential health affects of retirement, without relying solely on the most drastic measure of health, namely death. We focus on physical and mental health. It is expected that mental health is more responsive in the short run to changes in the individual environment therefore the effects of the act of retiring (if present) will be easier to detect. For mental health we use an indicator of depression derived from the Center for Epidemiologic Studies Depression Scale (CES-D, Radloff 1977). The CES-D measures emotional functioning (ranging from 0-8, with higher values being worse). An individual is considered to be depressed if the CES-D exceeds the clinically determined threshold level of five. As measures for physical health we include the outcome of the ADL test (values from 0-5, with higher values being worse), whether the individual has diabetes, and whether the individual has (had) cancer or a heart attack. It is important to note that the diabetes and cancer variables are derived from questions like "Has a doctor ever told you that you had ....." This implies that once individuals are observed to have a condition in one wave, they also have the condition in the following waves. We return to this issue in the beginning of section 5 where we discuss estimation issues. We also examine, whether the individual has high blood pressure, self reports about one's general health status (an indicator variable equal to one if the individual reports being in very good or excellent health), and mortality. We define retirement when people report to be out of the labor force, or not having any paid employment.

In order to complete the analysis, we make a variety of sample restrictions. First, we restrict the analyses to working males aged 50-70. This limits the sample to those who are at risk 11 
for retirement. Second, we limit the sample to those who are interviewed in at least two waves. ${ }^{6}$

Since the HRS is a panel dataset, these individuals are subsequently followed through 2004. Thus we examine individual health outcomes in the future due to past retirement behavior. We look at health outcomes 2 and 4 years after a potential retirement decision. We also stack the dataset for more observations. We continue to limit inclusion in the dataset to working in the base period. Thus an individual who is working in 1992 and 1994, but retires in 1998 would be in the dataset twice, while someone who works in 1992 and retires in 1994 would only be included once. We cluster the standard errors to take into account the multiple observations of the same person, as well as include control variables for the wave of interview.

The sample includes 3657 male workers of which 2158 are blue-collar workers and 2038 white- collar workers. As independent variables we include wave dummies, education, marital status, the number of children, wealth (in percentiles) age nonlinearly (age and age squared), and indicator variables for blue-collar worker, race, ethnicity, and foreign-born.

Table 1 reports sample averages for some important health variables and controls. Around $20 \%$ of the sample retires during our observation period. The table also confirms what Brown (2002) already concluded, namely that the sample of people who received a window offer is slightly younger and healthier than the sample as a whole. In section 4.1 we will further look at the relationship between health and the offering of a retirement window.

\subsection{Early Retirement Windows}

Early retirement windows are a limited-time offer, typically lasting six weeks to three months (Towers Perrin 1992). The HRS question starts with defining an early retirement window, stating:

"Employers sometimes encourage older workers to leave a firm at a particular time by offering a special financial incentive, like a cash bonus or improved pension benefits. These are often called "early retirement windows."

The respondents are then asked:

\footnotetext{
${ }^{6}$ Due to the mandatory time spent out of the labor market before being eligible for disability benefits and the time lag between disability application and benefit receipt, we have done specification tests limiting the sample to those who have never applied for disability benefits before 2004. The results are not quantitatively different, thus we report the results for the full sample here.
} 
"Have you ever been offered such an early retirement window on any job?"

The survey then solicits information on how many offers the individual has received, when the offer(s) was received, which employer made it, what was offered in the plan, and whether it was accepted. If the offer was accepted, they ask if the offer was influential in their decision to leave the job. If the offer was rejected, they ask if the offer would have induced a job change if the offer were doubled.

In total 444 workers out of the 3657 , or 16 percent of the sample, were offered a retirement window during our observation period. Of those receiving an early retirement window, $41 \%$ accept the offer and leave the employer.

We use the offering of a window as an instrument for retirement behavior. For this instrument to be valid, two conditions need to hold. First, the offering of a window should be predictive for retirement, as defined as out of the labor force, or not having any paid employment. A regression of retirement on the offering of a window and a set of other control variables ${ }^{7}$ reveals that the offering of a window is a strong predictor for retirement. A window increases the probability of retirement with about 11 percentage points. The F-statistic is 38.7 , which is well above the threshold value of 10 as suggested by Staiger and Stock (1997).

Second, the offering of the window should be uncorrelated with the outcome variable of interest (health in our case). We regressed the offering of a window in a time period $[t, t+2]$ on our health variables at time t. This regression also controls for white/blue-collar workers, age, age-squared, education, marital status, net worth deciles, race Hispanic, US born, the number of children and a wave of the interview indicator. As can be seen in table 2, none of the individual health variables is significant. Also of note is the fact that only job characteristics such as tenure on job, union status and blue collar work (including more detailed occupation categories included in specification checks) and the education and race of the individual predict early retirement window receipt, which may also be picking up characteristics of the job. Personal characteristics, such as marital status and number of children (including liking your job, finding your job stressful that were included in specification checks) are insignificant.

\footnotetext{
${ }^{7}$ These include white/blue-collar workers, age, age-squared, education, marital status, net worth deciles, race Hispanic, US born, the number of children and a wave of the interview indicator
} 


\section{Results}

This section presents the results of the health production models. We start with simple static models that include retirement as an explanatory variable along with a set of other control variables. These estimates are based on a comparison of the health status of those who retire early with those who retire later and hence measure the correlation between the health and retirement. Next we include estimates based on a dynamic model, equation (7'). Allowing for state dependence may be particularly relevant for health outcomes that are persistent. The retirement coefficient will now pick up the effect of retirement, given previous health status. For persistent health measures like cancer and diabetes, this retirement coefficient reflects the effect of the onset of the disease.

As argued in the previous sections, retirement is likely to be endogenous and therefore we also present estimates with retirement instrumented with the offering of an early retirement window. This model will give us the causal effect of retirement. For the dynamic models, we choose not to pursue further with Anderson-Hsiao (A-H) and Arellano-Bond (A-B) estimates. First, prime interest is in the effect of retirement on health and not in the effect of lagged health (or other exogenous characteristics). Since the offering of the retirement window is unrelated to previous health, it is expected that the simple dynamic model with instrumented retirement (the dynamic IV model) will give us the causal effect of retirement on health. Second, the health shock is permanent for some of our health variables (cancer and diabetes), which will invalidate the use of A-H and A-B estimators. ${ }^{8}$ We report the results of both the static IV and dynamic IV models, primarily for comparison. Both IV models provide consistent estimates of the causal effect of retirement on health. It should be noted, however, that the interpretation of the results of the two models differs, which is particularly relevant for health measures that display strong state dependence, such as cancer and diabetes.

\subsection{Baseline OLS results}

Table 3 reports the OLS estimates of a simple static model for different health measures. In these regressions we relate current health to a set of controls and a variable indicating whether or not the individual has retired in the preceding 2-year interval. The controls include indicators

${ }^{8}$ Blundell and Bond (1998) show that if health is persistent, such as a random walk, the differenced GMM performs badly because the lagged levels are poor instruments for changes in health. We have not estimated Blundell-Bond estimators because the stationarity assumption required for their method is also implausible in this context. 
for white/blue-collar worker, age, age squared, education, marital status, net worth deciles, race, Hispanic, US-born, the number of children, and a wave-of-interview indicator variable. Table 4 reports OLS estimates for dynamic health models. Besides the retirement coefficient we now also report the estimate of the lagged health variable. In both tables we correct the standard errors for repeated observations of the same person. The full tables, with all controls, are available upon request from the authors.

Table 3 shows that the partial correlation coefficients are, apart from the coefficient for high blood pressure, all strongly significant, suggesting that retirement is negatively correlated with one's health. For example, the chances of reporting good health decreases by almost 8.5 percent if retired. Similarly, chances of having diabetes, having cancer, having a heart attack, being depressed and having worse ADL scores increase with retirement. The dynamic estimation results of table 4 do not change this pattern. Allowing for state dependence reduces the magnitude of most coefficients. However, all but the coefficient for high blood pressure remain strongly significant. These results are in line with other studies that have relied on cross-sectional variation to assess the effect of retirement on health, such as Tsai et al (2005) and Dave et al (2006).

Of course it is difficult to interpret these findings as causal. The simple OLS estimates are derived from a direct comparison of those who retire early with those who retire later and it is, for instance, conceivable that health shocks in the interval $[t, t+2]$ have affected both health and the retirement decision. Furthermore, for some of the health measures included one may actually question whether the disease may manifest itself in such a short period. For instance, for cancer the OLS results of the dynamic model suggest that the onset of a cancer within 2 years increases by 2 percentage points. This is a large effect, given that the prevalence rate in the baseline wave is only 4 percent.

\subsection{IV estimates}

Tables 5 and 6 present IV estimates of the static and dynamic models. Both models lead to the simple conclusion that none of the significant effects found in the previous section remain. More precisely, the act of retirement does not have a negative impact on health within 2 years of retirement. For instance, depression is strongly positively related to retirement in the OLS regressions. The IV estimates of both the static and the dynamic model give about the same estimate, but with higher standard errors. Note that this cannot be due to a weak instrument problem as the first stage regressions showed strong and significant effects of the instrument on retirement. For some of the health variables we even find a change in the sign of the coefficient when retirement is instrumented. For instance, the positive and significant OLS estimate for the 
number of ADLs becomes negative and insignificant. The probability of reporting good health was significantly negatively affected by retirement in the OLS results. This IV results suggest that retirement leads to a 30 percent increase in the probability that an individual reports to be in good health. The effect is sizeable and significant at the $10 \%$ level. This finding is in line with the finding of Neuman (2007), who finds that retirement leads to significant improvement of selfreported health.

The estimates in Tables 5 and 6 refer to the short term (within 2 years) of retirement. For the self-reported health and a mental health variable like 'depression' it is likely that, retirement can have an impact on the relatively short run. This might also be the case for a variable like 'high blood pressure'. For physical measures like cancer or diabetes and probably also the number of ADLs short run effects are not likely. We therefore also estimated the longer run effects, by examining the effect of retirement in period $[t, t+2]$ on health at $t+4$. The IV results are reported in tables 7 and 8 for the static and dynamic model, respectively. The OLS results (not reported here) all confirm what we already found in tables 3 and 4 : retirement in $[t, t+2]$ is strongly negatively associated with health at $\mathrm{t}+4$. The IV estimates in tables 7 and 8 leads us to conclude again that retirement does not have a significant impact on health. There are, however, some important differences with the results of tables 5 and 6. First, the relatively large and positive effects of retirement on the probability of 'good health' have now vanished. This suggests that the effect of retirement on good health is temporary. Second, some variables like 'cancer' and 'diabetes' and show strong persistence or state dependence. This can be seen from the large and significant coefficient of the lagged health variable in the dynamic models. For these variables the IV estimates of the static model yield large and sometimes significant effects of retirement. The estimates of static models (whether it is IV or OLS) also pick up the lagged health effect. For these variables with strong persistence it is advisable to look at the effect of retirement on the onset of the disease, rather than on the prevalence, by using a dynamic model.

Since we are finding little effect of retirement on health, one robustness check is to see if we can pick up any causal relationship between retirement and mortality. If we do, it would indicate that we are potentially missing something with our earlier results, either we are choosing the health variables incorrectly, or mis-specifying the relationship. Table 9 presents the estimated effect of retirement on death as measured 4 (columns 1 and 2) and 6 (columns 3 and 4) years after the initial observation. Columns 1 and 3 present the OLS estimate, columns 2 and 4 report the IV results. The results of table 9 confirm our earlier findings. The OLS estimates hint at a strong statistical relationship. Retirement is correlated with increased mortality 4 years and 6 years afterwards, and these effects are sizable ( 2.5 percentage points and 4.1 percentage points for 
mortality 4 years and 6 years afterwards, respectively). However, in line with our results for the health variables, both effects become insignificant when retirement is instrumented.

There is also reason to suspect that the effect of retirement might differ between individuals, especially between those who might have different types of job. For example, a blue-collar worker with a physically demanding job might experience a different relationship between retirement and physical health than a white-collar worker. Tables 10 and 11 presents the results of the IV estimates of the dynamic model by different blue and white collar workers. The OLS results (not reported here) suggest strong negative effects on health of retirement. The IV estimates of the subsample of blue and white collar workers are very similar to the results of table 6 . The effects on self-reported health seem to be concentrated on white-collar workers. Retirement does not appear to have an effect on health. We also estimated the model for high (at least some college) and low educated workers. Also in these analyses the general picture that emerges is that there are little health effects of retirement. There one exception: the number of ADLs for higher educated workers. The dynamic IV estimates point at significant fewer ADLs (the coefficient equals -0.396 with a standard error of 0.197). This implies that retirement is good for the health (as measured by the ADL score) for higher educated workers. It is difficult to speculate about specific mechanisms that may lead to this result, but it could be that in retirement higher educated workers can engage more in mobility enhancing physical activities. The IV estimate of the static model points to an even larger effect (0.471 ), but this estimate is only significant at the $10 \%$ level. We also considered other subgroups, such as people who are working in a stressful job versus those who are not, or people who like their job versus those who do not. These analyses did not result in new insights. Again it appears that the simple OLS estimates of the static and dynamic models show strong and significant effects, but as soon as retirement is instrumented none of the significant effects remain.

Could it be that our finding of no health effects of retirement is due to our choice of instrument? We argued earlier that our instrument has strong predictive power, the $\mathrm{F}-$ test in the first stage regression equals 38.7, which far exceeds the value of 10 as suggested by Staiger and Stock (1997). Furthermore the offering of the window appeared to be unrelated to the health variables of interest. We also re-estimated our model with the instruments suggested by Charles (2002) and Neuman (2007). Both studies used the age specific incentives in the US social security system; an indicator for age 62 and age 65. The IV estimates using age 62 and age 65 as instruments agree with our previous estimates of tables 5 and 6 , where retirement is instrumented with the offering of a retirement window: retirement does not have any effect on health. There are however, two important differences. First, it appears in general that the IV estimates based on the social security ages are smaller in absolute value. This is in line with what we argued in section 3 : 
anticipation effects may bias the results of retirement towards zero. Second, for the variable 'good health' the IV estimates of the static model now become significant at the 5\% level (coefficient of 0.1972 and standard error of 0.0099). This is also what Neuman (2007) finds. He also presents IV estimates of a static health model and concludes that retirement has a positive effect on self reported health. It is good to note that the IV estimates of the dynamic model with age 62 and age 65 as instrument are not significant and hence confirm our finding that retirement does not have adverse effects on health.

\section{Conclusions}

This paper is concerned with the health effects of the act of retirement. This is an important question with pertinent policy consequences. As talk of raising retirement ages in pensions and social security schemes continues around the world, it is important to know both the costs and benefits for the individual as well as the government or pension fund's budgets and health care expenditures. Up to now there are only a few studies that address this question.

The notion that retirement harms health is an old and persistent hypothesis. Indeed, OLS estimates confirm that retirement is always associated with worse health outcomes. These effects are strongly significant and hold for a range of health variables. It is argued in earlier studies in the retirement literature and in some recent papers in this area (Charles 2002, Neuman 2007, Bound and Waidmann 2008, Coe and Zamarro 2008) that health and work choices may be endogenously related. We use the offering of an early retirement window as an instrument for retirement. Accounting for the fact that health and retirement are jointly determined changes the results dramatically.

The IV estimates suggest that there are no negative health effects of retirement. These findings hold for different types of workers and are robust with respect to the use of different instruments. If anything, early retirement has a positive, but temporary, impact on self-reported health, whether this captures well-being, satisfaction, or different measures of health that we are not able to measure with the survey. However, this temporary increase does not seem to manifest itself in other health measures in the short run (within two years) or long run (within four years or mortality up to 6 years later). We also find some evidence of improvements in health for highlyeducated workers, as measured by the number of ADL limitations. 
Since the effects are small and temporary, this reinforces the notion that recent trends in labor force participation and longevity are independent phenomena. Further, since the measured effects are larger when retirement is unexpected, indicating that changes in public policy, such as the increases in the normal retirement age, are even less likely to have an effect for the demand for medical care or Medicare spending directly.

The question that remains is whether this finding of no health effects of retirement is plausible. It is likely that there are little effects of retirement on diseases like cancer and diabetes in the short run to medium long run ( 2 to 4 years). Changes in the local environment and related changes in life styles may affect the likelihood of getting these diseases, but it is also very likely that it takes much longer than 2 or 4 years for these diseases to manifest themselves. The strong effects measured while using OLS for these diseases are therefore not plausible. There is a recent literature examining the relationship between Health and Socio-Economic Status (SES): much of the association between SES and health during middle age and old age is driven by a causal effect of health on SES, rather than the other way around. (See Adams et al. (2003) for the relation between wealth and health for an older population (70+) and Smith (2007) for a younger $(<60)$ population. Case and Deaton (2006) find that much of the differences in health across the income distribution are driven by health-related absence from the labor force.) Our finding of minimal health effects of retirement are in line with these findings. 


\section{References}

Adams, O., L. Lefebvre (1981) "Retirement and Mortality." Aging and Work; 4:115-120.

Adams, P., M.D. Hurd, D. McFadden, A. Merrill and T. Ribeiro (2003) Healthy, Wealthy, and Wise? Tests for Direct Causal Paths between Health and Socioeconomic Status, Journal of Econometrics, 112: 3-56.

Atchley, R.C. (1976) “The Sociology of Retirement.” New York: Halsted Press.

Blundell, R., and S. Bond. (1998) "Initial conditions and moment restrictions in dynamic panel data models." Journal of Econometrics 87: 11\{143.

Bound, John and Timothy Waidmann (2008), Estimating the Health Effects of Retirement" University of Michigan Retirement Research Center Working Paper, July, 2008 .

Bradford, Leland P. (1979) “Can You Survive Your Retirement?” Harvard Business Review 57(4): 103-109.

Brown, Charles (2002) "Early Retirement Windows" University of Michigan Retirement Research Center Working Paper, WP 2002-028.

Brown, Charles (2003) "Early Retirement Windows" University of Michigan Retirement Research Center Working Paper, WP 2003-064.

Carp, F.M (1967) “Retirement Crisis.” Science 157:102-3.

Case, Anne and Angus Deaton (2006), Broken Down by Sex and Work: How our Health Declines, Chapter 6 in Analyses in the Economics of Aging, 2005, University of Chicago Press, pp. 185-205.

Casscells W, D. Evans, R. DeSilva, J.E. Davies, C.H. Hennekens, B. Rosner, B. Lown, M.J. Jesse. (1980) "Retirement and Coronary Mortality." Lancet; I(8181): 1288-1289.

Charles K. K. (2002) "Is Retirement Depressing? Labor Force Inactivity and Psychological Well-being in Later Life." NBER working paper 9033.

Coe, Norma B. and Gema Zemarro (2008) "Retirement effects on Health in Europe." RAND working paper series WR-588, June.

Dave, Dhval, Inas Rashad and Jasmina Spasojevic. (2006) “The Effect of Retirement on Physical and Emotional Health Outcomes." NBER working paper W12123, March.

Ekerdt, David J., Raymond Bosse, JS LoCastro. (1983) "Claims that Retirement Improves Health.” Journal of Gerontology 38. 
Eisdorfer, C. and F. Wilkie. (1977) "Stress, Disease, Aging and Behavior." In James E. Birren and K. Warnere Shaie (eds) Handbook of he Phsychology of Aging. New York: Van Nostrand, Reinhold. Pg.251-75.

Gonzales, E.R. (1980) "Retiring May Predispose to Fatal Heart Attack." Journal of the American Medical Association; 243:13-14.

Grossman, Michael (1972) "On the Concept of Health Capital and the Demand for Health" Journal of Political Economy, 80, No. 2, pp 223-255.

Haynes, SG, AJ McMichael, HA Tyroler. (1978) "Survival After Early and Normal Retirement." Journal of Gerontology; 33:269-278.

Kasl, S.V. (1980) "The Impact of Retirement." in C.L. Cooper and R. Payne (eds) Current Concerns in Occupational Stress. New York: John Wiley.

Kerkhofs M. and M. Lindeboom (1997) "Age Related Health Dynamics and Changes in Labor Market Status" Health Economics, 6, 407-424.

Lindeboom, Maarten, France Portrait, Gerard J. van den Berg. (2002) "An Econometric Anaylsis of the Mental-Health Effects of Major Events in the Life of Older Individuals." Health Economics.

MacBride, A. (1976) "Retirement as a Life Crisis: Myth or Reality?" Canadian Psychiatric Association Journal 72:547-56.

Minkler, Merideth (1981) "Research on he Health Effects of Retirement: An Uncertain Legacy" Journal of Health and Social Behavior, Vol. 22, No 2 (June) 117-130.

Neuman, Kevin (2007) "Quit Your Job and Get Healthier? The Effect of Retirement on Health" Journal of Labor Research.

Niemi, T (1980) "Retirement and Mortality." Scandinavian Journal of Social Medicine; $8: 39-41$.

Radloff, L. S. (1977) "The CES-D scale: A self-report depression scale for research in the general population” Applied Psychological Measurement, 1, 385-401.

Rowland, KF (1977) "Environmental Events Predicting Death for the Elderly." Psychological Bulletin; 84:349-372.

Sheppard, H.L. (1976) "Work and Retirement." In Robert H. Binstock and Ethel Shanas, Handbook of Aging and the Social Sciences. New York: Van Nostrand, Reinhold. Pg 286-306. 
Smith, J.P. (2003) Consequences and Predictors of New Health Events. NBER working paper series 10063.

Smith, J.P. (2007) The Impact of SES on Health over the Life Course. Journal of Human Resources, , 42(4):739-764, Fall 2007..

Staiger, D. and J.H. Stock (1997), Instrumental Variables Regression with Weak Instruments, Econometrica $65,557-586$.

Time (1983). “Open Windows: Incentives to Resign or Retire.” Monday Feb 21. Available http://www.time.com/time/magazine/article/0,9171,925907,00.html

Towers Perrin (1992) "More Employers Opening Retirement Windows" Monitor Newsletter, September, Issue 134, pp. 1-3.

Tsai, Shan P, Judy K Wendt, Robin P Donnelly, Geert de Jong, Farah S. Ahmed. (2005) "Age at Retirement and Long Term Survival of an Industrial Population: Pospective Cohort Study." British Medical Journal, doi:10.1136/bmj.38586.448704.EO. Oct 21.

Watson Wyatt Insider (2001) “Employers' Report on Early Retirement Windows" December.

http://www.watsonwyatt.com/us/pubs/insider/showarticle.asp?ArticleID=9225\&Compon $\underline{\text { ent }=\text { The+Insider }}$ 


\begin{tabular}{|c|c|c|}
\hline Variable & Whole Sample & Offered Window \\
\hline \multicolumn{3}{|l|}{ Demographics } \\
\hline Age & 59.19 & 57.64 \\
\hline Years of Education & 12.53 & 14.00 \\
\hline Married & 0.85 & 0.85 \\
\hline Hispanic & 0.05 & 0.03 \\
\hline No. Of Children & 3.59 & 3.09 \\
\hline Blue collar & 0.55 & 0.36 \\
\hline \multicolumn{3}{|l|}{ Baseline Health } \\
\hline Good Health & 0.54 & 0.64 \\
\hline Depressed (CES-D8 >4) & 0.02 & 0.01 \\
\hline High Blood Pressure & 0.34 & 0.34 \\
\hline Number of ADL's & 0.41 & 0.37 \\
\hline Diabetes & 0.10 & 0.10 \\
\hline Cancer & 0.04 & 0.04 \\
\hline $\begin{array}{l}\text { Heart Attack } \\
\text { 2-years later }\end{array}$ & 0.03 & 0.04 \\
\hline Out of the Labor Force & 0.19 & 0.27 \\
\hline Receive a Window & 0.06 & 1.00 \\
\hline Good Health & 0.50 & 0.62 \\
\hline Depressed (CES-D8 >4) & 0.02 & 0.02 \\
\hline High Blood Pressure & 0.36 & 0.33 \\
\hline Number of ADL's & 0.51 & 0.59 \\
\hline Diabetes & 0.12 & 0.11 \\
\hline Cancer & 0.06 & 0.05 \\
\hline Heart Attack & 0.02 & 0.01 \\
\hline Observations & 11,047 & 714 \\
\hline
\end{tabular}


Table 2: Retirement Window Offerings are Orthogonal to Health ${ }^{1}$

\begin{tabular}{|c|c|c|c|c|c|c|c|}
\hline $\begin{array}{l}\text { Offered a Retirement } \\
\text { Window }(t, t+2)\end{array}$ & Good health & $\begin{array}{l}\text { Depressed } \\
(\text { CESD-8>4) }\end{array}$ & $\begin{array}{l}\text { High blood } \\
\text { pressure }\end{array}$ & $\#$ of ADL & Diabetes & Cancer & Heart Attack \\
\hline \multirow[t]{2}{*}{ Health Measure at $t$} & 0.0068 & 0.0011 & 0.0092 & -0.0020 & 0.0115 & 0.0156 & 0.0212 \\
\hline & $(0.0056)$ & $(0.0142)$ & $(0.0056)$ & $(0.0047)$ & $(0.0081)$ & $(0.0125)$ & $(0.0170)$ \\
\hline \multirow[t]{2}{*}{ Union member } & $0.0529 * * *$ & $0.0537 * * *$ & $0.0532 * * *$ & $0.0530 * * *$ & $0.0530 * * *$ & $0.0529 * * *$ & $0.0529 * * *$ \\
\hline & $(0.0085)$ & $(0.0087)$ & $(0.0085)$ & $(0.0085)$ & $(0.0085)$ & $(0.0085)$ & $(0.0085)$ \\
\hline \multirow[t]{2}{*}{ Tenure on Job } & $0.0029 * * *$ & $0.0030 * * *$ & $0.0029 * * *$ & $0.0029 * * *$ & $0.0029 * * *$ & $0.0029 * * *$ & $0.0029 * * *$ \\
\hline & $(0.0003)$ & $(0.0003)$ & $(0.0003)$ & $(0.0003)$ & $(0.0003)$ & $(0.0003)$ & $(0.0003)$ \\
\hline Tenure & $0.0823 * * *$ & $0.0803 * * *$ & $0.0814 * * *$ & $0.0818 * * *$ & $0.0814 * * *$ & $0.0816 * * *$ & $0.0818 * * *$ \\
\hline Unknown & $(0.0177)$ & $(0.0182)$ & $(0.0177)$ & $(0.0177)$ & $(0.0177)$ & $(0.0176)$ & $(0.0177)$ \\
\hline \multirow[t]{2}{*}{$<$ HS Education } & $0.0183 * *$ & $0.0197 * * *$ & $0.0188 * * *$ & $0.0189 * * *$ & $0.0189 * * *$ & $0.0188 * * *$ & $0.0190 * * *$ \\
\hline & $(0.0072)$ & $(0.0074)$ & $(0.0072)$ & $(0.0072)$ & $(0.0072)$ & $(0.0072)$ & $(0.0072)$ \\
\hline \multirow[t]{2}{*}{ HS Degree } & $0.0201 * *$ & $0.0222 * *$ & $0.0209 * *$ & $0.0211 * *$ & $0.0211 * *$ & $0.0208 * *$ & $0.0211 * *$ \\
\hline & $(0.0086)$ & $(0.0087)$ & $(0.0085)$ & $(0.0085)$ & $(0.0085)$ & $(0.0085)$ & $(0.0085)$ \\
\hline \multirow[t]{2}{*}{ Some College } & $0.0481 * * *$ & $0.0496 * * *$ & $0.0495 * * *$ & $0.0493 * * *$ & $0.0493 * * *$ & $0.0493 * * *$ & $0.0495 * * *$ \\
\hline & $(0.0108)$ & $(0.0108)$ & $(0.0105)$ & $(0.0105)$ & $(0.0105)$ & $(0.0105)$ & $(0.0105)$ \\
\hline \multirow[t]{2}{*}{ Married } & -0.0040 & -0.0041 & -0.0043 & -0.0042 & -0.0042 & -0.0043 & -0.0044 \\
\hline & $(0.0080)$ & $(0.0082)$ & $(0.0080)$ & $(0.0080)$ & $(0.0080)$ & $(0.0080)$ & $(0.0080)$ \\
\hline \multirow[t]{2}{*}{ Caucasian } & $0.0361 * *$ & $0.0394 * *$ & $0.0363 * *$ & $0.0363 * *$ & $0.0378 * *$ & $0.0361 * *$ & $0.0360 * *$ \\
\hline & $(0.0163)$ & $(0.0177)$ & $(0.0165)$ & $(0.0162)$ & $(0.0168)$ & $(0.0162)$ & $(0.0162)$ \\
\hline \multirow[t]{2}{*}{ Black } & $0.0475 * * *$ & $0.0525 * * *$ & $0.0465 * * *$ & $0.0475 * * *$ & $0.0482 * * *$ & $0.0472 * * *$ & $0.0474 * * *$ \\
\hline & $(0.0175)$ & $(0.0189)$ & $(0.0177)$ & $(0.0174)$ & $(0.0179)$ & $(0.0174)$ & $(0.0173)$ \\
\hline Number of & -0.0013 & -0.0015 & -0.0014 & -0.0013 & -0.0014 & -0.0013 & -0.0013 \\
\hline Children & $(0.0012)$ & $(0.0013)$ & $(0.0012)$ & $(0.0012)$ & $(0.0012)$ & $(0.0012)$ & $(0.0012)$ \\
\hline Obs & 11049 & 10735 & 11047 & 11049 & 11047 & 11046 & 11049 \\
\hline $\mathrm{R}$-squared & 0.08 & 0.08 & 0.08 & 0.08 & 0.08 & 0.08 & 0.08 \\
\hline
\end{tabular}

Robust standard errors in parentheses

* significant at 10\%; $* *$ significant at $5 \%$; *** significant at $1 \%$

1: Regressions also contain: controls for white/blue-collar worker, age, age squared, net worth deciles, US-born, indicator for physical job, and a wave-of-interview indicator. 
Table 3: OLS results for static health production models ${ }^{1}$

\begin{tabular}{llllllll}
\hline Health at $\mathrm{t}+2$ & Good health & $\begin{array}{l}\text { Depressed } \\
(\mathrm{CESD}-8>4)\end{array}$ & $\begin{array}{l}\text { High blood } \\
\text { pressure }\end{array}$ & \# of ADL & Diabetes & Cancer & Heart Attack \\
\hline Retired $(\mathrm{t}, \mathrm{t}+2)$ & $-0.0845^{* * *}$ & $0.0286^{* * *}$ & 0.0119 & $0.1369^{* * *}$ & $0.0270^{* *}$ & $0.0218^{* * *}$ & $0.0338^{* * *}$ \\
& $(0.0121)$ & $(0.0051)$ & $(0.0114)$ & $(0.0161)$ & $(0.0085)$ & $(0.0068)$ & $(0.0050)$ \\
R-squared & 0.09 & 0.03 & 0.16 & 0.78 & 0.05 & 0.04 & 0.01 \\
Number of obs & 11047 & 9294 & 11047 & 11055 & 11049 & 11045 & 11055 \\
\hline
\end{tabular}

Robust standard errors in parentheses. * significant at 10\%; ** significant at 5\%; *** significant at $1 \%$

1; Regressions also contain: controls for white/blue-collar worker, age, age squared, education, marital status, net worth deciles, race, Hispanic, US-born, the number of children, and a wave-of-interview indicator variable.

Table 4: OLS results for dynamic health production models ${ }^{1}$

\begin{tabular}{llllllll}
\hline Health at $\mathrm{t}+2$ & Good health & $\begin{array}{l}\text { Depressed } \\
(\mathrm{CESD}-8>4)\end{array}$ & $\begin{array}{l}\text { High blood } \\
\text { pressure }\end{array}$ & \# of ADL & Diabetes & Cancer & Heart Attack \\
\hline Retired(t, $\mathrm{t}+2)$ & $-0.0546^{* * *}$ & $0.0271^{* * *}$ & 0.0050 & $0.1334 * * *$ & $0.0117 *$ & $0.0199 * * *$ & $0.0333^{* * *}$ \\
& $(0.0109)$ & $(0.0050)$ & $(0.0091)$ & $(0.0154)$ & $(0.0067)$ & $(0.0052)$ & $(0.0049)$ \\
Health at $\mathrm{t}$ & $0.4458^{* * *}$ & $0.1922^{* * *}$ & $0.5622^{* * *}$ & $0.4404 * * *$ & $0.6850^{* * *}$ & $0.7606 * * *$ & $0.1047 * *$ \\
& $(0.0109)$ & $(0.0363)$ & $(0.0065)$ & $(0.0441)$ & $(0.0120)$ & $(0.0177)$ & $(0.0193)$ \\
R-squared & 0.27 & 0.05 & 0.43 & 0.80 & 0.44 & 0.44 & 0.03 \\
Number of obs & 11047 & 10458 & 11047 & 11055 & 11049 & 11045 & 11055 \\
\hline
\end{tabular}

Robust standard errors in parentheses. * significant at 10\%; ** significant at 5\%; *** significant at $1 \%$

1: Regressions also contain: controls for white/blue-collar worker, age, age squared, education, marital status, net worth deciles, race, Hispanic, US-born, the number of children, and a wave-of-interview indicator variable. 
Table 5: IV results for static health production models ${ }^{1}$

\begin{tabular}{llllllll}
\hline Health at $\mathrm{t}+2$ & Good health & $\begin{array}{l}\text { Depressed } \\
(\text { CESD-8 }>4)\end{array}$ & $\begin{array}{l}\text { High blood } \\
\text { pressure }\end{array}$ & \# of ADL & Diabetes & Cancer & Heart Attack \\
\hline Retired $(\mathrm{t}, \mathrm{t}+2)$ & $0.4358^{*}$ & 0.0287 & 0.1795 & -0.1199 & 0.2198 & 0.0326 & -0.0316 \\
& $(0.2311)$ & $(0.0577)$ & $(0.1939)$ & $(0.1205)$ & $(0.1350)$ & $(0.0958)$ & $(0.0503)$ \\
Adj R-squared & 0.20 & 0.03 & 0.14 & 0.77 & 0.00 & 0.03 & 0.01 \\
Number of obs & 11047 & 10458 & 11047 & 11055 & 11049 & 11045 & 11055 \\
\hline
\end{tabular}

The instrument is the offering of an early retirement window between $t$ and $t+2$.

Robust standard errors in parentheses. * significant at 10\%; ** significant at 5\%; *** significant at $1 \%$

1; Regressions also contain: controls for white/blue-collar worker, age, age squared, education, marital status, net worth deciles, race, Hispanic, US-born, the number of children, and a wave-of-interview indicator variable.

Table 6: IV results for dynamic health production models ${ }^{1}$

\begin{tabular}{llllllll}
\hline Health at $\mathrm{t}+2$ & Good health & $\begin{array}{l}\text { Depressed } \\
\text { (CESD-8>4) }\end{array}$ & $\begin{array}{l}\text { High blood } \\
\text { pressure }\end{array}$ & \# of ADL & Diabetes & Cancer & Heart Attack \\
\hline Retired $(\mathrm{t}, \mathrm{t}+2)$ & $0.3087^{*}$ & 0.0289 & -0.0061 & -0.1107 & 0.0873 & -0.0388 & -0.0421 \\
& $(0.1728)$ & $(0.0554)$ & $(0.1424)$ & $(0.1051)$ & $(0.1003)$ & $(0.0649)$ & $(0.0475)$ \\
Health at $\mathrm{t}$ & $0.4612^{* * *}$ & $0.1920^{* * *}$ & $0.5623^{* * *}$ & $0.4434 * * *$ & $0.6822^{* * *}$ & $0.7611^{* * *}$ & $0.1068^{* * *}$ \\
& $(0.0132)$ & $(0.0364)$ & $(0.0066)$ & $(0.0451)$ & $(0.0126)$ & $(0.0176)$ & $(0.0195)$ \\
Adj R-squared & 0.19 & 0.04 & 0.43 & 0.79 & 0.43 & 0.43 & 0.03 \\
Number of obs & 11047 & 10458 & 11047 & 11055 & 11049 & 11045 & 11055 \\
\hline
\end{tabular}

The instrument is the offering of an early retirement window between $t$ and $t+2$.

Robust standard errors in parentheses. * significant at $10 \%$; ** significant at 5\%; *** significant at $1 \%$

1: Regressions also contain: controls for white/blue-collar worker, age, age squared, education, marital status, net worth deciles, race, Hispanic, US-born, the number of children, and a wave-of-interview indicator variable. 
Table 7: IV results for static health production models: four years ahead ${ }^{1}$

\begin{tabular}{llllllll}
\hline Health at $\mathrm{t}+4$ & Good health & $\begin{array}{l}\text { Depressed } \\
(\text { CESD-8>4) }\end{array}$ & $\begin{array}{l}\text { High blood } \\
\text { pressure }\end{array}$ & \# of ADL & Diabetes & Cancer & Heart Attack \\
\hline Retired(t, $t+4)$ & 0.0918 & 0.0555 & 0.2367 & 0.0925 & $0.2798^{*}$ & 0.2149 & 0.0876 \\
& $(0.2138)$ & $(0.0646)$ & $(0.2362)$ & $(0.1927)$ & $(0.1669)$ & $(0.1391)$ & $(0.0648)$ \\
Adj R-squared & 0.07 & 0.02 & 0.00 & 0.73 & 0.03 & 0.03 & 0.01 \\
Number of obs & 9287 & 8680 & 9287 & 9293 & 9290 & 9286 & 9294 \\
\hline
\end{tabular}

The instrument is the offering of an early retirement window between $\mathrm{t}$ and $\mathrm{t}+2$.

Robust standard errors in parentheses. * significant at 10\%; ** significant at 5\%; *** significant at $1 \%$

1; Regressions also contain: controls for white/blue-collar worker, age, age squared, education, marital status, net worth deciles, race, Hispanic, US-born, the number of children, and a wave-of-interview indicator variable.

Table 8: IV results for dynamic health production models: four years ahead ${ }^{1}$

\begin{tabular}{llllllll}
\hline Health at $\mathrm{t}+4$ & Good health & $\begin{array}{l}\text { Depressed } \\
(\text { CESD-8 }>4)\end{array}$ & $\begin{array}{l}\text { High blood } \\
\text { pressure }\end{array}$ & \# of ADL & Diabetes & Cancer & Heart Attack \\
\hline Retired $(\mathrm{t}, \mathrm{t}+4)$ & -0.0204 & 0.0535 & -0.0173 & 0.0885 & 0.0753 & 0.1125 & 0.0779 \\
& $(0.1744)$ & $(0.0624)$ & $(0.1468)$ & $(0.1823)$ & $(0.1137)$ & $(0.0947)$ & $(0.0630)$ \\
Health at $\mathrm{t}$ & $0.4080^{* * *}$ & $0.2115^{* * *}$ & $0.7597 * * *$ & $0.4805 * * *$ & $0.8636^{* * *}$ & $0.8478^{* * *}$ & $0.0743 * * *$ \\
& $(0.0136)$ & $(0.0412)$ & $(0.0089)$ & $(0.0643)$ & $(0.0116)$ & $(0.0197)$ & $(0.0194)$ \\
Adj R-squared & 0.24 & 0.04 & 0.47 & 0.75 & 0.48 & 0.35 & 0.02 \\
Number of obs & 9287 & 8680 & 9287 & 9293 & 9290 & 9286 & 9294 \\
\hline
\end{tabular}

The instrument is the offering of an early retirement window between $\mathrm{t}$ and $\mathrm{t}+2$.

Robust standard errors in parentheses. * significant at 10\%; ** significant at 5\%; *** significant at $1 \%$

1: Regressions also contain: controls for white/blue-collar worker, age, age squared, education, marital status, net worth deciles, race, Hispanic, US-born, the number of children, and a wave-of-interview indicator variable. 
Table 9: Effect of retirement on Mortality four years ahead $(t+4)$ and six years ahead $(t+6)$

\begin{tabular}{lllll}
\hline & \multicolumn{2}{l}{ Mortality within four years } & \multicolumn{2}{l}{ Mortality within six years } \\
\hline Mortality & OLS & IV & OLS & IV \\
\hline Retired $(\mathrm{t}, \mathrm{t}+2)$ & $0.0250^{* * *}$ & -0.0533 & $0.0413^{* * *}$ & 0.0072 \\
& $(0.0047)$ & $(0.0414)$ & $(0.0070)$ & $(0.0700)$ \\
Observations & 10078 & 10078 & 8753 & 8753 \\
R-squared & 0.12 & 0.08 & 0.08 & 0.08 \\
\hline
\end{tabular}

Robust standard errors in parentheses

* significant at $10 \% ; * *$ significant at $5 \%$; *** significant at $1 \%$

Note: Regressions also contain: controls for white/blue-collar worker, age, age squared, education, marital status, net worth deciles, race, Hispanic, US-born, the number of children, and a wave-of-interview indicator variable.

Table 10: Blue collar workers: IV results for dynamic health production models ${ }^{1}$

\begin{tabular}{llllllll}
\hline Health at $\mathrm{t}+2$ & Good health & $\begin{array}{l}\text { Depressed } \\
\text { (CESD-8>4) }\end{array}$ & $\begin{array}{l}\text { High blood } \\
\text { pressure }\end{array}$ & \# of ADL & Diabetes & Cancer & Heart Attack \\
\hline Retired(t, $\mathrm{t}+2)$ & 0.1391 & 0.0819 & -0.1276 & -0.0063 & 0.0932 & -0.0059 & -0.0924 \\
& $(0.2927)$ & $(0.1146)$ & $(0.2152)$ & $(0.2188)$ & $(0.1467)$ & $(0.0962)$ & $(0.1178)$ \\
Health at t & $0.4016^{* * *}$ & $0.1816^{* * *}$ & $0.5616^{* * *}$ & $0.4170^{* * *}$ & $0.6863^{* * *}$ & $0.7527^{* * *}$ & $0.1328^{* * *}$ \\
& $(0.0216)$ & $(0.0428)$ & $(0.0092)$ & $(0.0574)$ & $(0.0176)$ & $(0.0252)$ & $(0.0337)$ \\
Adj R-squared & 0.18 & 0.02 & 0.42 & 0.76 & 0.43 & 0.43 & 0.08 \\
Number of obs & 6085 & 5701 & 6085 & 6091 & 6083 & 6087 & 5064 \\
\hline
\end{tabular}

The instrument is the offering of an early retirement window between $t$ and $t+2$.

Robust standard errors in parentheses. * significant at 10\%; ** significant at 5\%; *** significant at $1 \%$

1: Regressions also contain: controls for white/blue-collar worker, age, age squared, education, marital status, net worth deciles, race, Hispanic, US-born, the number of children, and a wave-of-interview indicator variable. 
Table 11: White collar workers: IV results for dynamic health production models ${ }^{1}$

\begin{tabular}{llllllll}
\hline Health at $\mathrm{t}+2$ & Good health & $\begin{array}{l}\text { Depressed } \\
(\text { CESD-8>4) }\end{array}$ & $\begin{array}{l}\text { High blood } \\
\text { pressure }\end{array}$ & \# of ADL & Diabetes & Cancer & Heart Attack \\
\hline Retired $(\mathrm{t}, \mathrm{t}+2)$ & $0.4062^{*}$ & -0.0036 & 0.0335 & -0.1618 & 0.0830 & -0.0764 & 0.0482 \\
& $(0.2219)$ & $(0.0579)$ & $(0.1947)$ & $(0.1073)$ & $(0.1388)$ & $(0.0893)$ & $(0.0555)$ \\
Health at $\mathrm{t}$ & $0.5255^{* * *}$ & $0.2143^{* * *}$ & $0.5616^{* * *}$ & $0.5180^{* * *}$ & $0.6759 * * *$ & $0.7689^{* * *}$ & $0.0762 * * *$ \\
& $(0.0174)$ & $(0.0676)$ & $(0.0100)$ & $(0.0791)$ & $(0.0192)$ & $(0.0253)$ & $(0.0246)$ \\
Adj R-squared & 0.19 & 0.03 & 0.43 & 0.84 & 0.44 & 0.42 & 0.01 \\
Number of obs & 4962 & 4757 & 4962 & 4964 & 4961 & 4958 & 4230 \\
\hline
\end{tabular}

The instrument is the offering of an early retirement window between $t$ and $t+2$.

Robust standard errors in parentheses. * significant at 10\%; ** significant at 5\%; *** significant at $1 \%$

1: Regressions also contain: controls for white/blue-collar worker, age, age squared, education, marital status, net worth deciles, race, Hispanic, US-born, the number of children, and a wave-of-interview indicator variable. 